

\title{
Synthesis of Zeolite from Sugar Cane as Detergent Builder: Variation of Si/Al Ratio and Hydrothermal Time
}

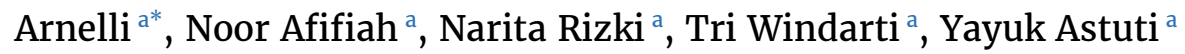 \\ a Physical Chemistry Laboratory, Chemistry Department, Faculty of Sciences and Mathematics, Diponegoro Un4ersity, Jalan Prof. \\ Soedarto, Tembalang, Semarang \\ * Corresponding author: arnelli@live.undip.ac.id
}

Article Info

Keywords:

Synthetic zeolite, builder, detergent
Kata Kunci:

Zeolit sintetik, builder, detergensi

\section{Abstract}

Synthesis of zeolite from bagasse with variation of $\mathrm{Si} / \mathrm{Al}$ ratio $(1,2,1,4,1,6$ and 1,8) with ZS1-ZS5 code and hydrothermal time $(160,190,250,340$, and 460 minutes) with sample code ZSa - ZSe has been conducted. The synthesized zeolite was then applied to the detergent builder. The detergent builder of synthetic zeolite was used as a substitute for sodium tripolyphosphate, which is not environmentally friendly as it can lead to eutrophication. One of the detergent builder functions is to improve the washing efficiency of the surfactant by inactivating water-absorbing minerals $\left(\mathrm{Ca}^{2+}\right.$ and $\mathrm{Mg}^{2+}$ ions) which may further deter the detergency process. Zeolites were synthesized using a sol-gel method followed by a hydrothermal process. The material used in this synthesis is $\mathrm{Na}_{2} \mathrm{SiO}_{3}$ (aq) (derived from bagasse) mixed with $\mathrm{NaAl}(\mathrm{OH})_{4}$ (aq), then stirred to form a white gel and continued by heating using autoclave at $100^{\circ} \mathrm{C}$. The results obtained are zeolite-A and zeolt- $\mathrm{X}$ for variation of $\mathrm{Si} / \mathrm{Al}$ ratio and hydrothermal time variation, with $\mathrm{CEC}$ value and detergency proportional to $\mathrm{Si} / \mathrm{Al}$ ratio and hydrothermal time.

\section{Abstrak}

Sintesis zeolit dari ampas tebu dengan variasi rasio Si/Al $(1 ; 1,2 ; 1,4 ; 1,6 ;$ dan 1,8$)$ dengan kode ZS1-ZS5 dan waktu hidrotermal (160, 190, 250, 340, dan 460 menit) dengan kode sampel ZSa - ZSe telah dilakukan. Zeolit hasil sintesis selanjutnya diaplikasikan untuk builder detergen. Builder detergen dari zeolit sintesis digunakan sebagai pengganti natrium tripoli fosfat, yang tidak ramah lingkungan karena dapat mengakibatkan eutrofikasi. Salah satu fungsi builder pada detergen adalah meningkatkan efisiensi pencuci dari surfaktan dengan cara menonaktifkan mineral yang penyebab kesadahan air (ion $\mathrm{Ca}^{2+}$ dan $\mathrm{Mg}^{2+}$ ) yang selanjutnya dapat menghalangi proses detergensi. Zeolit disintesis menggunakan metode sol-gel yang dilanjutkan dengan proses hidrotermal. Bahan yang digunakan dalam sintesis ini yaitu Na2SiO3(aq) (berasal dari ampas tebu) yang dicampur dengan $\mathrm{NaAl}(\mathrm{OH}) 4(\mathrm{aq})$, kemudian diaduk hingga membentuk gel putih dan dilanjutkan dengan pemanasan menggunakan autoclave pada suhu $100^{\circ} \mathrm{C}$. Hasil yang diperoleh berupa zeolit-A dan zeolt-X untuk variasi ratio Si/Al dan variasi waktu hidrotermal, dengan nilai KTK dan detergensi berbanding lurus dengan rasio Si/Al dan waktu hidrotermal.

\section{Pendahuluan}

Tebu (Saccharum officinarum $L$ ) merupakan tanaman yang dimanfaatkan niranya untuk pembuatan gula. Kandungan nira dalam tebu hanya $10 \%$ sedangkan sisanya berupa ampas tebu (90\%). Selama ini ampas tebu digunakan sebagai bahan bakar pada pabrik gula dan meninggalkan sisa abu yang kurang dimanfaatkan. Abu ampas tebu memiliki kandungan silika yang cukup tinggi sehingga dapat dimanfaatkan sebagai sumber silika dalam sintesis zeolit. Zeolit memiliki kemampuan 
pertukaran kation yang dimanfaatkan sebagai builder pada industri deterjen, builder pada detergen berfungsi meningkatkan efisiensi pencucian [1, 2].

Zeolit mengandung kation-kation untuk menstabilkan muatan zeolit serta sejumlah molekul air dan memiliki kemampuan melakukan pertukaran kation [3, 4]. Kation-kation tersebut dapat dipertukarkan dengan kation lain, kemampuan inilah yang banyak dimanfaatkan di industri, salah satunya pada industri deterjen, fungsi bulider diantaranya menurunkan kesadahan air dengan cara pertukaran ion natrium dari zeoli dengan ion lain penyebab kesadahan air (ion $\mathrm{Ca}^{2+}$ dan $\mathrm{Mg}^{2+}$ ) yang dapat menghalangi proses detergensi [5]. Zeolit X dan zeolit A memiliki daya tukar kation yang maksimum sehingga dapat diaplikasikan sebagai adsorben, penukar ion dan khususnya builder deterjen [6].

Rasio $\mathrm{SiO}_{2} / \mathrm{Al}_{2} \mathrm{O}_{3}$ pada zeolit menentukan ukuran kristal serta morfologi kristal zeolit yang dihasilkan [7]. Purnomo $d k k$. [8] telah berhasil mensintesis zeolit Na-A dan $\mathrm{Na}-\mathrm{X}$ dari abu ampas tebu dimana pengaruh rasio Si/Al pada sintesis zeolit ini mempengaruhi lama waktu dari pembentukan inti kristal serta jenis kristal yang dihasilkan. Shirazi $d k k$. [9] menyatakan bahwa setiap zeolit memiliki kekhasan pada rasio $\mathrm{Si} / \mathrm{Al}$, meningkatnya rasio akan berpengaruh terhadap ukuran kristal dan luas permukaan dari zeolit yang terbentuk.

Penelitian ini bertujuan untuk mensintesis zeolit dari abu ampas tebu dengan variasi $\mathrm{SiO}_{2} / \mathrm{Al}_{2} \mathrm{O}_{3}$ dan waktu hifrotermal terhadap jenis mineral dan ukuran bulir dari zeolit sintetik dan zeolit sintetik diaplikasikan untuk builder pada deterjensi Sodium Lauryl Sulfate (SLS).

\section{Metode Penelitian}

\section{Alat dan Bahan}

Alat-alat gelas, alat hidrotermal, X-Ray Difractometer (XRD) Shimadzhu X-2000. Natrium hidroksida (Merck), sekam padi , $\mathrm{Al}(\mathrm{OH})_{3}$ (Merck), aquades, aquabides,

\section{Cara kerja}

Zeolit disintesis dengan menggunakan metode SolGel yang dilanjutkan dengan proses Hidrotermal. Bahan yang digunakan dalam sintesis ini yaitu $\mathrm{Na}_{2} \mathrm{SiO}_{3}$ (aq) yang dicampur dengan $\mathrm{NaAl}(\mathrm{OH})_{4}$ (aq), kemudian diaduk hingga membentuk gel putih dan dilanjutkan dengan pemanasan menggunakan autoclave pada suhu $100^{\circ} \mathrm{C}$ yang bervariasi selama $160,190,250,340$, dan 460 menit dengan kode sampel ZSa - ZSe. Variasi ratio Si/Al dibuat $1 ; 1,2 ; 1,4 ; 1,6$; dan 1,8 dengan kode ZS1-ZS5.. $\mathrm{Na}_{2} \mathrm{SiO}_{3}$ (aq) diperoleh dari hasil reaksi fusi (peleburan) abu yang dicampur dengan $\mathrm{NaOH}$ pada $500^{\circ} \mathrm{C}$ selama 1jam, produk yang diperoleh digerus hingga halus sampai tercampur rata kemudian dilarutkan ke dalam akuades dan didiamkan selama 24jam lalu diambil filtratnya. $\mathrm{NaAl}(\mathrm{OH})_{4}(\mathrm{aq})$ diperoleh dari reaksi antara $\mathrm{NaOH}$ dengan $\mathrm{Al}(\mathrm{OH})_{3}$. Zeolit yang terbentuk dikarakterisasi menggunakan XRD untuk mengetahui jenis mineral yang terbentuk, nilai KTK, kemudian zeolit sintesis diaplikasikan sebagai builder pada detergensi surfaktan SLS dengan pembanding Sodium TriPolyPhosphate (STPP).

\section{Hasil dan Pembahasan}

Pembentukan zeolit dimulai dari mereaksikan $\mathrm{Na}_{2} \mathrm{SiO}_{3}$ (aq) dan $\mathrm{NaAl}(\mathrm{OH})_{4}(\mathrm{aq})$, proses pembentukan zeolit diawali dengan terbentuknya fase meta stabil yaitu pembentukan gel berwarna putih yang kemudian terjadi perpindahan atau migrasi ion dan diakhiri fase stabil atau terbentuknya kristal zeolit [10]. Anion silikat $\left(\mathrm{SiO}_{4}^{-}\right)$bereaksi cepat dengan $\mathrm{Al}(\mathrm{OH})_{4}^{-}$membentuk senyawa aluminosilikat terutama sodalit $\left(\mathrm{Na}_{4} \mathrm{Al}_{3} \mathrm{O}_{12} \mathrm{OH}\right)$, dimana sodalit merupakan mineral pembentuk zeolit $\mathrm{A}$. Pada larutan alkali, aluminium memberikan muatan negatif $\left[\mathrm{Al}(\mathrm{OH})_{4}\right]^{-}$tetrahedral, selama perlakuan hidrotermal struktur yang lain bergabung membentuk kerangka zeolit [11].

Gel amorf terlarut akan mengalami penataan ulang strukturnya yang disebabkan oleh pemanasan untuk membentuk fase yang merupakan embrio inti kristal pada tahap pembentukan kristal. Pada tahap pertumbuhan kristal, gel amorf perlahan membentuk embrio inti kristal kemudian terjadi pertumbuhan kristal sampai gel amorf habis dan terbentuk kristal dalam keadaan stabil . Reaksi pembentukan polimer zeolit digambarkan sebagai berikut:<smiles>CO[Si](O)(O)O[Si](O)(O)O[Na]</smiles>

Gambar 1. Reaksi pembentukan polimer zeolit

\section{Karakterisasi dengan XRD: Variasi rasio Si/Al}

Data yang diperoleh dari XRD berupa intensitas, sudut ( $2 \theta$ ), dan jarak antar bidang (d) yang dapat digunakan untuk menentukan jenis mineral zeolit dengan membandingkan data dari pola difraksi sinar-X JCPDS-ICDD. Data JCPDS-ICDD yang digunakan meliputi nomor 12-0246 (zeolit X (Na)/ $\mathrm{Na}_{2} \mathrm{Al}_{2} \mathrm{Si}_{2.4} \mathrm{O}_{8.8} 6.7 \mathrm{H}_{2} \mathrm{O}$ ), dan nomor 39-0222 (zeolit A (Na)/ $\mathrm{Na}_{96} \mathrm{Al}_{96} \mathrm{Si}_{96} \mathrm{O}_{384} 216$ $\mathrm{H}_{2} \mathrm{O}$ ). Berikut difraktogram zeolit sintesis: 


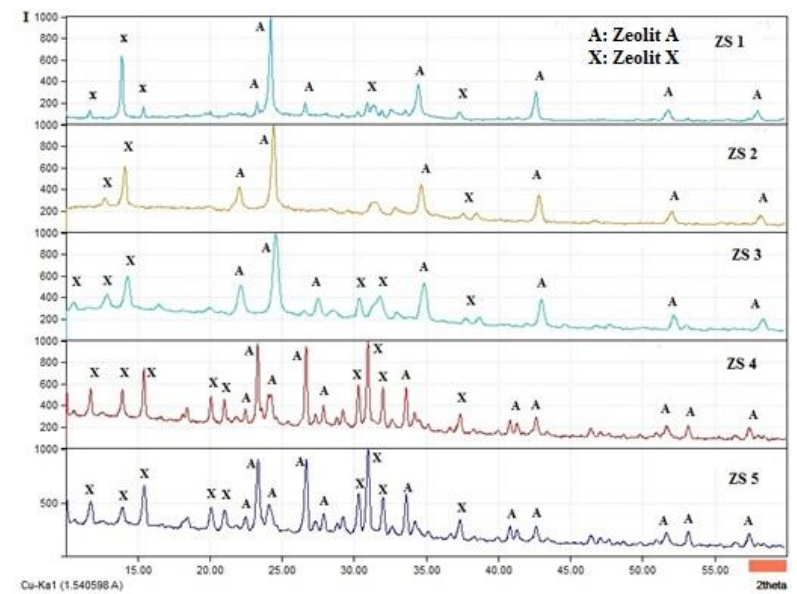

Gambar 2. Difraktogram Lima Variasi Zeolit Hasil Sintetik

Gambar 2 menunjukkan hasil analisa XRD pada kelima sampel zeolit sintetik dengan keterangan A dan $\mathrm{X}$ pada puncak XRD berturut-turut merupakan jenis mineral zeolit yang terbentuk yaitu zeolit A dan zeolit $\mathrm{X}$ dengan kation penyeimbang natrium (Na). Pola difraktogram pada ZS1 hingga ZS3 hampir sama dengan intensitas tertinggi muncul pada daerah $2 \theta: 24,19^{\circ}$ namun pada $\mathrm{ZS}_{4}$ dan $\mathrm{ZS} 5$ terjadi pergeseran intensitas tertinggi yang muncul pada daerah $2 \theta: 30,94^{\circ}$ hal ini karena bidang kristal yang terbentuk pada $2 \theta: 24,19^{\circ}$ runtuh kemudian membentuk bidang baru pada daerah $2 \theta: 30,94^{\circ}$. Jumlah puncak utama pada tiap variasi zeolit mengalami kenaikan. Hal ini ditunjukkan pada ZS1 memiliki puncak utama berjumlah 3, ZS2 berjumlah 4, ZS3 berjumlah 5 dan ZS4 serta ZS5 berjumlah 7. Puncak yang selalu ada pada hasil variasi berada pada $2 \theta$ sekitar 14 dan 24. Puncak baru pada ZS4 dan ZS5 muncul pada daerah $2 \theta: 23,26 ; 26,64$ hingga 32,1. Tabel berikut menunjukkan adanya mineral yang hilang berdasarkan perubahan intensitas relatif pada hasil zeolit.

Tabel 1: Perubahan Intensitas Relatif pada Zeolit Hasil

\begin{tabular}{cccccccc}
\hline \multirow{2}{*}{$2 \theta$} & \multirow{2}{*}{$\mathrm{d}(\AA)$} & \multicolumn{5}{c}{ \% Intensitas Relatif } & \multirow{2}{*}{ Jenis Zeolit } \\
\cline { 3 - 7 } & & ZS1 & ZS2 & ZS3 & ZS4 & ZS5 & \\
\hline 23,26 & 3,8196 & 14 & - & - & - & - & $\mathrm{A}$ \\
23,29 & 3,8148 & - & - & - & 91 & - & $\mathrm{A}$ \\
23,43 & 3,7923 & - & - & - & - & 80 & $\mathrm{~A}$ \\
\hline 26,60 & 3,3471 & 15 & - & - & - & - & $\mathrm{A}$ \\
26,64 & 3,3422 & - & - & - & 89 & - & $\mathrm{A}$ \\
26,76 & 3,3274 & - & - & - & - & 84 & $\mathrm{~A}$ \\
\hline 30,26 & 2,95 & - & - & - & 49 & - & $\mathrm{X}$ \\
30,35 & 2,9415 & - & - & 41 & - & - & $\mathrm{X}$ \\
30,40 & 2,9368 & - & - & - & - & 47 & $\mathrm{X}$ \\
\hline 30,89 & 2,8913 & 14 & - & - & - & - & $\mathrm{X}$ \\
30,94 & 2,8868 & - & - & - & 100 & - & $\mathrm{X}$ \\
31,06 & 2,8759 & - & - & - & - & 100 & $\mathrm{X}$ \\
\hline 31,76 & 2,8141 & - & - & 12 & - & - & $\mathrm{X}$ \\
31,98 & 2,7952 & - & - & - & 48 & - & $\mathrm{X}$ \\
32,1 & 2,7850 & - & - & - & - & 44 & $\mathrm{X}$ \\
\hline
\end{tabular}

Berdasarkan tabel 2 diketahui bahwa jarak antar bidang (d) semakin kecil mengikuti pergeseran puncak difraktogram kearah $2 \theta$ yang lebih tinggi. Hal ini

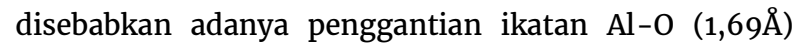
dengan ikatan yang lebih pendek $\mathrm{Si}-\mathrm{O}(1,61 \AA)$ sehingga terjadi perubahan panjang kerangka pada zeolit yang mengakibatkan unit sel mengkerut [12].

Karakterisasi XRD; Variasi waktu hidrotermal

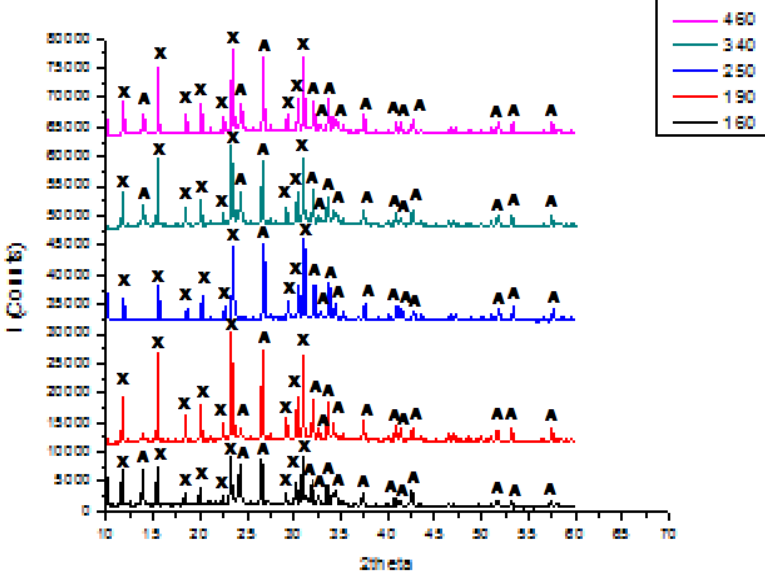

Gambar 3. Difraktogram Lima Variasi Zeolit Hasil Sintetik

Berdasarkan gambar 3 terlihat pola difraktogram keseluruhan variasi waktu hidrotermal sama dan pada intensitas yang sering muncul tertinggi memiliki perbedaan yaitu dari nilai FWHM puncak-puncaknya yang berfluktuasi. Jenis mineral yang terbentuk adalah zeolit A dan zeolit $\mathrm{X}$ dengan kation penyeimbang $\mathrm{Na}^{+}$. Secara umum pola difraktogram (gambar 3) hampir sama. Perubahan dapat dilihat pada tabel 2 di bawah ini:

Tabel 2: Perubahan Intensitas Relatif

\begin{tabular}{|c|c|c|c|c|c|c|c|}
\hline \multirow{2}{*}{$2 \theta\left(^{\circ}\right)$} & \multicolumn{5}{|c|}{ Intensitas Relatif (\%) } & \multirow{2}{*}{$\begin{array}{l}\text { Jenis } \\
\text { Zeolit }\end{array}$} & \multirow{2}{*}{ FWHM } \\
\hline & 160 menit & 190menit & 250menit & 340 menit & 460menit & & \\
\hline 13,88386 & - & - & - & 29,3992 & - & A & 0,18098 \\
\hline 13,91915 & 74,849 & - & - & - & - & A & 0,13104 \\
\hline 13,95898 & - & - & - & - & 24,9384 & A & 0,16995 \\
\hline 24,19551 & - & - & - & 44,3365 & - & A & 0,22844 \\
\hline 24,20416 & - & 14,2812 & - & - & - & A & 0,19737 \\
\hline 24,21789 & 82,8408 & - & - & - & - & A & 0,22751 \\
\hline 24,27406 & - & - & - & - & 36,4018 & A & 0,23243 \\
\hline
\end{tabular}

Beberapa perubahan ini terjadi pada zeolit tipe A, sedangkan untuk zeolit $\mathrm{X}$ hampir sering muncul pada setiap sudut. Untuk mensintesis zeolit dengan kadar $\mathrm{Si}$ rendah misal zeolit A akan diikuti dengan terbentuknya zeolit Si rendah lain yaitu zeolit X [8].

\section{Nilai Kapasitas Tukar Kation (KTK)}

Kapasitas tukar kation (KTK) adalah salah satu metode yang digunakan untuk mengetahui kemampuan zeolit dalam pertukaran kation. Banyaknya kation (dalam miliek4alen) yang dapat dijerap oleh zeolit per satuan berat zeolit (per 100 gr) dinamakan Kapasitas Tukar Kation (KTK). Kation $\mathrm{Ca}^{2+}$ dan $\mathrm{Mg}^{2+}$ yang ada pada air dapat meningkatkan kesadahan air, kation tersebut dapat digantikan oleh kation $\mathrm{Na}^{+}$yang ada pada kerangka zeolit, hal ini yang dinamakan pertukaran kation oleh zeolit.Kation $\mathrm{Ca}^{2+}$ sisa pada larutan sampel ditentukan konsentrasinya untuk mengetahui banyaknya konsentrasi $\mathrm{Ca}^{2+}$ yang dapat ditukarkan dengan kation $\mathrm{Na}^{+}$pada zeolit. Hasil kapasitas tukar kation pada zeolit hasil sintetik adalah sebagai berikut: 
Tabel 3: Hasil Kapastitas Tukar Kation Zeolit Sintetik variasi rasio $\mathrm{Si} / \mathrm{Al}$

\begin{tabular}{cc}
\hline Sampel & KTK (mek/100 g) \\
\hline ZS1 & 146 \\
ZS2 & 116 \\
ZS3 & 140 \\
ZS4 & 272 \\
ZS5 & 278 \\
\hline
\end{tabular}

Tabel 4: Hasil Kapastitas Tukar Kation Zeolit Sintetik variasi hidrotermal

\begin{tabular}{cc}
\hline Zeolit & $\begin{array}{c}\text { KTK } \\
\text { mek } / 100 \mathrm{~g}\end{array}$ \\
\hline Zsa & 228,00 \\
ZSb & 146,40 \\
ZSc & 151,20 \\
ZSd & 230,00 \\
Zse & 242,00 \\
\hline
\end{tabular}

Dari tabel 3 dan tabel 4 terlihat bahwa ada kecendrungan semakin besar ratio SI/AL dan semakin besar waktu hidrotermal semakin besar pula nilai kapasitas tukar kation, hal ini berbanding lurus dengan kation Na yang terdapat dalam zeolit.

\section{Detergensi}

Proses detergensi dapat dianalisa dengan membandingkan berat kain bersih, berat kain kotor, dan berat kain setelah pencucian dengan detergen. Kain bersih (awal) dikotori dengan kotoran standar kemudian dikeringkan. Kain kering ditimbang dan dicatat sebagai berat kain kotor, presentase kotoran yang menempel dinyatakan dalam persamaan 1.

$$
P K=\frac{B K K-B B B}{B B B} \times 100 \%(1)
$$

PK merupakan persen kotoran yang menempel pada substrat, BKK merupakan berat kain kotor, dan BBB merupakan berat kain bersih

Kain kotor dicuci dengan larutan detergen dengan waktu tertentu, dikeringkan dan ditimbang. Persen kehilangan kotoran dihitung dengan persamaan 2.

$$
P K^{\prime}=\frac{B K K-B B B^{\prime}}{B B B^{\prime}} \times 100 \% \text { (2) }
$$

PK' merupakan persen berkurangnya kotoran , BKK merupakan berat kain kotor dan BBB' merupakan berat kain bersih setelah pencucian

Persen detergensi ditentukan dengan persamaan 3.

$$
\text { Detergensi }=\frac{P K \prime}{P K} \times 100 \% .(3)
$$

PK' merupakan persen berkurangnya kotoran dan PK merupakan persen kotoran yang menempel.
Tabel 5: Deterjensi SLS: variasi rasio Si/Al

\begin{tabular}{cc}
\hline Sampel & Deterjensi (\%) \\
\hline SLS + ZS1 & 86,10 \\
SLS + ZS2 & 78,04 \\
SLS + ZS3 & 81,56 \\
SLS + ZS4 & 97,01 \\
SLS + ZS5 & 97,55 \\
SLS + STTP & 71,35 \\
SLS & 48,70 \\
\hline
\end{tabular}

Tabel 6: Deterjensi SLS: variasi Waktu hidrotermal

\begin{tabular}{cc}
\hline Sampel & $\begin{array}{c}\text { Deterjensi } \\
(\%)\end{array}$ \\
\hline SLS + Zsa & 80,90 \\
SLS + ZSb & 74,55 \\
SLS + ZSc & 71,80 \\
SLS + ZSd & 85,92 \\
SLS + ZSe & 87,73 \\
STPP+SLS & 53,32 \\
SLS & 30,55 \\
\hline
\end{tabular}

Tabel 5 dan Tabel 6 menunjukkan detergensi dari sls dengan adanya zeolit sintesis (SLS+Zeolit sitesis) dibandingkan dengan detergensi SLS +STPP (Sodium Tri Poli Phosphat) dan detergensi SLS tanpa builder, dertegensi mengunakan buider zeolit sintesis lebih besar dari detergensi dengan builder STPP baik untuk variasi rasio $\mathrm{Si} / \mathrm{Al}$ maupun variasi waktu hidrotermal. Detergensi SLS dengan builder zeolit sintesis berkisar antara $78,04 \%$ - 97,55\% untuk variasi ratio $\mathrm{Si} / \mathrm{Al}$, sedangkan untuk variasi waktu hidrotermal berkisar antara $71,80 \%-87,73 \%$. Detergensi SLS + zeolit sintesis variasi rasio $\mathrm{Si} / \mathrm{Al}$ lebih besar dari variasi waktu hidrotermal, hal ini disebabkan pada sintesis zeolit dengan variasi waktu hidrotermal menggunankan rasio $\mathrm{Si} / \mathrm{Al}$ adalah 1, jadi semakin tinggi rasio $\mathrm{Si} / \mathrm{Al}$ semakin tinggi pula detergensi dari SLS, tertinggi 97,55\%

\section{Kesimpulan}

Sintesis zeolit dari abu ampas tebu dengan variasi rasio SI/Al dan variasi waktu hidrotermal menghasilkan campuran zeolit-A dan zeolit-X, semakin tinggi rasio SI/Al dan waktu hidrotermal semakin besar pula nilak KTK dan Detergensi SLS.

\section{Daftar Pustaka}

[1] Wempie Gressangga, Suhartana Suhartana, Parsaoran Siahaan, Studi Kemampuan Adsorpsi Zeolit Alam Terdealuminasi terhadap Senyawa Fenol dan 2-Metoksifenol pada Asap Cair Sekam Padi: Eksperimen dan Komputasi AB Initio, Jurnal Kimia Sains dan Aplikasi, 14, 3, (2011) 94-99

[2] Muslimin Muslimin, Taslimah Taslimah, Rahmad Nuryanto, Studi Pembuatan dan Karakterisasi Membran Pervaporasi Berbahan Dasar Zeolit Alam, Jurnal Kimia Sains dan Aplikasi, 17, 2, (2014) 65-69

[3] Claudia Belviso, Francesco Cavalcante, Antonio Lettino, Saverio Fiore, Zeolite synthesised from 
fused coal fly ash at low temperature using seawater for crystallization, Coal Combustion and Gasification Products, $\quad 1, \quad 1, \quad$ (2009) 8-1 http://dx.doi.org/10.4177/CCGP-D-09-00004.1

[4] Fitri Lutfiana Rahayu, Rahmad Nuryanto, Linda Suyati, Pengaruh Diameter Kanal Pelet Katalis Zeolit Aktif dan Ni-Zeolit terhadap Pirolisis Limbah Batang Pohon Sagu (Metroxylonsp.), Jurnal Kimia Sains dan Aplikasi, 16, 1, (2013) 33-37

[5] J. S. Udhoji, Amit Kumar Bansiwal, S. U. Meshram, S. S. Rayalu, Improvement in optical brightness of fly ash based zeolite-A for use as detergent builder, Journal of Scientific and Industrial Research, 64, (2005) 367-371

[6] Sanja Bosnar, Josip Bronić, Đurđica Brlek, Boris Subotić, Chemically controlled particulate properties of zeolites: Towards the face-less particles of zeolite A. 2. Influence of aluminosilicate batch concentration and alkalinity of the reaction mixture (hydrogel) on the size and shape of zeolite A crystals, Microporous and Mesoporous Materials, 142, 1 12011) 389-397 http://dx.doi.org/10.1016/j.micromeso.2010.12.027

[7] Cleo Kosanović, Tatjana Antonić Jelić, Josip Bronić, Damir Kralj, Boris Subotić, Chemically controlled particulate properties of zeolites: Towards the faceless particles of zeolite A. Part 1 . Influence of the batch molar ratio [SiO2/Al2O3]b on the size and shape of zeolite A crystals, Microporous and Mesoporous Materials, 137, 1, (2011) 72-82 http://dx.doi.org/10.1016/j.micromeso.2010.08.024

[8] Chandra Wahyu Purnomo, Chris Salim, Hirofumi Hinode, Synthesis of pure $\mathrm{Na}-\mathrm{X}$ and $\mathrm{Na}-\mathrm{A}$ zeolite from bagasse fly ash, Microporous and Mesoporous Materials, 162, (2012) 6-13 http://dx.doi.org/10.1016/j.micromeso.2012.06.007

[9] L Shirazi, E Jamshidi, MR Ghasemi, The effect of Si/Al ratio of ZSM- 5 zeolite on its morphology, acidity and crystal size, Crystal Research and Technology, 43, 12, (2008) 1300-1306

[10] Ramsharan Singh, Prabir K Dutta, MFI: a case study of zeolite synthesis, Handbook of Zeolite Science and Technology, 35, (2003) 21-64

[11] Keka Ojha, Narayan C. Pradhan, Amar Nath Samanta, Zeolite from fly ash: synthesis and characterization, Bulletin of Materials Science, 27, 6, (2004) 555-564 http://dx.doi.org/10.1007/bf02707285

[12] Halimaton Hamdan, Introduction to Zeolites: Synthesis, Characterization, and Modification, Universiti Teknologi Malaysia, Kualalumpur, 1992. 